\title{
DESE NVOLVIMENTO DE UM SISTEMA PARA RECOMENDAÇÃO DE ADUBAÇÃO PARA A CULTURA DA BANANEIRA ${ }^{(1)}$
}

\author{
Fábio Henrique Tavares de Oliveira ${ }^{(2)}$, Roberto Ferreira Novais ${ }^{(3)}$, \\ Víctor Hugo Alvarez V.(3) \& Reinaldo Bertola Cantarutti ${ }^{(3)}$
}

\begin{abstract}
RESUMO
As recomendações de adu bação para a cultura da bananeira devem ser mais confiáveis do ponto de vista técnico e, princi palmente, mais propensas a ajustes com bases científicas, em relação às tabelas. 0 objetivo deste trabalho foi desenvolver um sistema para estimar doses de nutrientes a serem recomendadas para a cultura da bananeira (FERTICALC ${ }^{\circledR}-$ Bananei ra), por meio da modelagem do balanço nutricional. $O$ balanço nutricional é obtido pela diferença entre o requerimento do nutriente pela cultura e seu suprimento pelo solo e resíduos vegetais. Se o requerimento for mai or que o suprimento, recomenda-se a aplicação de fertilizante; se for inferior ou igual ao suprimento, não se recomenda a aplicação de fertilizante. Simulações mostraram que as doses de nutrientes a serem recomendadas pelo FE RTICALC ${ }^{\circledR}$-Bananeira aumentam continuamente com o aumento da produtividade esperada e com a di minui ção dos teores desses nutrientes no solo, sendo maiores no primei ro ciclo e menores a partir do segundo ciclo. Considerando a lógica envolvida em sua constituição e as variáveis utilizadas na modelagem do FERTICALC ${ }^{\circledR}$-Bananeira, este sistema constitui importante alternativa para recomendação de adubação para a cultura da bananeira.
\end{abstract}

Termos de indexação: banana, balanço nutricional, requerimento de nutrientes, suprimento de nutrientes, modelagem.

\footnotetext{
(1) Parte da Tese de Doutorado do primeiro autor apresentada, ao Programa de Pós-Graduação em Solos e Nutrição de Plantas da Universidade Federal de Viçosa - UFV. Recebido para publicação em novembro de 2003 e aprovado em novembro de 2004.

(2) Professor Adjunto do Departamento de Solos e Engenharia Rural do Centro de Ciências Agrárias da Universidade Federal da Paraíba - UFPB. Campus Universitário, CEP 58397-000 Areia (PB). E-mail: fabio@cca.ufpb.br

(3) Professor do Departamento de Solos da Universidade Federal de Viçosa - UFV. Av. PH Rolfs s/n, CEP 36570-000 Viçosa (MG). E-mail: rfnovais@ufv.br; vhav@ufv.br; cantarutti@ufv.br
} 


\title{
SUMMARY: DEVELOPMENT OF A FERTILIZATION RECOMMENDATION SYSTEM FOR BANANA PLANTATIONS
}

\begin{abstract}
Fertilizer recommendations for banana plantations should betechnically sound and, mainly, more adjustable on a scientific base than the usual recommendation tables. A system was devel oped to esti materecommendablenutrient doses for banana (FE RTICALC @Bananeira), by means of modeling nutrient balance. This nutrient balanceis obtained by thedifferencebetween thecrop nutrient demand and supply through soil and plant residues. When the demand is higher than thesupply, fertilizer application is recommended; when it is lower or equal to the supply, fertilizer application is not recommended. Simulations showed that the recommendable nutrient doses by the FERTICALC $®$-Bananeira increase continuously with the expected productivity rise and the reduction of nutrient contents in the soil that are higher in the first cycle and lower from the second cycle on. The FERTICALC $\otimes-B a n a n e$ ra represents an important alternative for the recommendation of fertilizers for banana plantations due to the underlying logic and variables.
\end{abstract}

Index terms: banana, nutrient bal ance, nutrient demand, nutrient supply, modeling.

\section{NTRODUÇÃO}

Dentre os diversos fatores que influenciam o crescimento e o desenvolvimento da bananeira, a nutrição é decisiva para obtenção de alta produtividade, uma vez que as plantas apresentam crescimento rápido e acumulam quantidades elevadas de nutrientes (Lahav, 1995; López M. \& Espinosa M., 1995). Baixas produtividades da bananeira muitas vezes estãoassociadas à utilização de solos de baixa fertilidade e ao suprimento inadequado de nutrientes durante o ciclo da cultura (Borges et al., 1999).

As tabelas utilizadas no País que recomendam a adubação para a cultura da bananeira têm seus méritos, mas apresentam a desvantagem de não considerarem que as doses recomendadas dos nutrientes variam continuamente com a produtividade esperada, com o teor e com a capacidade tampão do nutriente no solo (Oliveira, 2002). Essas tabelas apresentam forte empirismo envolvido na sua constituição e a falta de perspectivas futuras quanto a uma evolução mais bem sustentada cientificamente (N ovais \& Alvarez V., 2000). Assim, propõe-se que as recomendações de adubação para a cultura da bananeira sejam mais confiáveis do ponto de vista técnicoe, principal mente, mais propensas a ajustes com bases científicas, em relação às tabelas, mediante o desenvolvimento e utilização de sistemas para recomendação de adubação baseados em model os matemáticos (Tomé J únior \& Novais, 2000; Oliveira, 2002; ToméJ únior, 2004).

Os modelos apresentam uma síntese lógica do conhecimento sobre o sistema de produção e fornecem descrições quantitativas dos processos que neleacontecem. A modelagem pode, desta maneira, revel ar lacunas no conhecimento vigente e fornecer caminhos para futuras pesquisas (Rao et al., 1982; Dourado Neto et al., 1998a; Novais \& Smyth, 1999; Oliveira, 2002). Dessa forma, a modelagem permite a evolução segura de um sistema de recomendação de adubação, por sugerir mudanças cada vez mais refinadas, pela fundamentação lógica de sua constituição.

Quantoà complexidade, os model os matemáticos, em geral, são classificados em mecanísticos e empíricos. Nos modelos mecanísticos, os processos são quantificados com base no conhecimento científico atual, tornando-os bastante complexos e demandando dados que, muitas vezes, são dificilmenteobtidos na prática. Os modelos empíricos consistem de funções que descrevem relações entre variáveis, sem se referirem aos processos envolvidos. Um bom modelo deve ser resultante de uma combinaçãoideal entremecanicidade (complexidade) eempirismo (simplicidade) e deve demandar poucas informações, as quais não devem ser de difícil obtençãona prática. Sua estrutura deveser flexível o suficiente para permitir a introdução de novas infor mações ou idéias, à medida que o conhecimento científico for evoluindo (Booteet al., 1996; Monteith, 1996; Passioura, 1996; Dourado Neto et al., 1998a,b).

Para recomendação de adubação, algumas pressuposições podem ser simplificadas e incorporadas a modelos mecanísticos. Essas simpl ificações normal mente envol vem diminuição no nível de detalhes e desconsi der ação de processos que quantitativamente são de menor importância, o que diminui bastante a quantidade de informações exigidas para alimentar o model o (Rao et al., 1982; Geypens \& Vandendriessche, 1996). I sso torna o model o suficientemente simples, para permitir seu entendimento e utilização, mas suficientemente complexo, para permitir sua utilização mais abrangente (Dourado Neto et al., 1998b). 
Um método eficiente e de boa exatidão para estimar a necessidade de adubação de uma cultura, o qual satisfaz os princípios das leis gerais da adubação, é o do balanço nutricional. Esse método tem sido recomendado para calcular a necessidade de adubação nitrogenada para a cultura do milho nos Estados Unidos (Stanford, 1973) e, mais recentemente, no Brasil, para cal cular a necessidade de adubação para eucalipto (Barros et al., 1995), milho (Carvalho, 2000), tomate (Mello, 2000), arroz irrigado (Raffaeli, 2000), café (Prezotti, 2001; Novais et al., 2002), cana-de-açúcar (Freire, 2001), soja (Santos, 2002), coqueiro (Rosa, 2002), bananeira (Oliveira, 2002), algodão (Possamai, 2003) e pastagem (Santos, 2003).

Estetrabal ho teve como obj etivo desenvolver um sistema para recomendação de adubação para a cultura da bananeira, por meio da modelagem do requerimento e do suprimento de nutrientes, de modo que suas doses recomendadas variem continuamente com a produtividade esperada e com os teores e capacidade tampão dos nutrientes no sol o.

\section{MATERIAL E MÉTODOS}

\section{Desenvolvimento do sistema}

Na modelagem do Sistema para Recomendação de Adubação para a Cultura da Bananeira (FERTICALC ${ }^{\circledR}$-Bananeira), foram combinados modelos mecanísticos e empíricos, com vistas em utilizar a menor quantidade possível de informações para alimentá-lo ("inputs"), sem prejudicar a exatidão das recomendações. O FERTICALC ${ }^{{ }_{-}}$ Bananeira também foi estruturado de modo a permitir sua atualização, na medida em que novas informações fossem publicadas na literatura ou produzidas pelo próprio usuário.

As recomendações a partir do FERTICALC ${ }^{{ }_{-}}$ Bananeira baseiam-se no balanço nutricional entre perdas e ganhos de nutrientes no sistema soloplanta, sendo obtido pela diferença entre o requerimento do nutriente pela cultura e seu suprimento pelo solo e pelos resíduos vegetais. Se esta diferença for positiva (requerimento maior que suprimento), recomenda-se a aplicação de fertilizante; se for negativa ou nula (requerimento inferior ou igual ao suprimento), não se recomenda a aplicação de fertilizante. O FERTICALC ${ }^{\circledR}$ Bananeira expressa tanto o requerimento (REQ) quanto o suprimento do nutriente (SUP) em termos de dose, devendo ser a diferença entre ambos igual à dose recomendada (DR) do nutriente via fertilizante:

$$
\mathrm{DR}=\mathrm{REQ}-\mathrm{SUP}
$$

NoFERTICALC ${ }^{\circledR}$-Bananeira, orequerimento de cada nutriente écal culado com base na demanda da cultura para atingir determinada produtividade esperada por ciclo de produção. A bananeira é uma planta pereneque apresenta perfil hamento, de modo que, geralmente, são conduzidos, simultaneamente, em cada touceira, três indivíduos (mãe-filho-neto) compondo uma "família". Com a col heita do cacho da planta-mãe, encerra-se o primeiro ciclo de produção. Depois, a planta-filha terminará seu crescimento e, com a col heita de seu cacho, encerrase o segundo ciclo. Com a col heita do cacho da planta-neta, obtém-se a produção do terceirocicloe, assim, sucessivamente (Alves \& Oliveira, 1999; Souto et al., 1999). Dessa forma, as recomendações deadubação geradas peloFERTICALC-Bananeira $\AA$ serão diferenciadas entre o primeiro ciclo de produção e os demais (Martin-Prével, 1985).

Para desenvolver o FERTICALC ${ }^{\circledR}$-Bananeira buscaram-se, na literatura, dados de crescimento e acumulação de nutrientes nas diversas partes da planta (Oliveira, 2002). Para a bananeira crescer, desenvolver e produzir, ela terá de acumular quantidades el evadas de nutrientes nos tecidos vegetativos e reprodutivos. Por ocasião da col heita, parte dos nutrientes imobilizados nessa biomassa é exportada ("ráquis feminina" +engaço + frutos), mas a restante (rizoma + pseudocaule + fol has + coração + "ráquis masculina") é restituída ao solo, após a decomposição dos resíduos. A discriminação da planta em biomassa exportada e restituída ao sol o é fundamental, não somente porque as quantidades de nutrientes acumuladas nestas partes das plantas são diferentes, mas também pel o fato de a bi omassa restituída ao solo após a colheita ser importante fonte denutrientes para as plantas que permanecem na área e para a manutenção da fertilidade do sol o. Os dados encontrados na literatura fornecem informações apenas sobre a parte da planta-mãe exportada e a restituída ao solo, por ocasião da colheita. No FERTICALC ${ }^{\circledR}$-Bananeira, não se contabilizam as quantidades de nutrientes imobilizados nos perfilhos desbastados, por consi derar que, quantitativamente, esses val ores são pequenos e que esses nutrientes voltarão ao solo e depois serão contabilizados na análise de solo.

Uma vez que o crescimento e o acúmulo de nutrientes pela bananeira dependem do grupo genômico do cultivar, o FERTICALC ${ }^{\circledR}$-Bananeira considerou separadamente dois grupos decultivares: AAA e AAB. Para estimar o requerimento de um nutriente pela cultura, esse sistema depende inicialmente de informação sobre a produtividade esperada (Figura 1). Estabelecida a produtividade esperada, osistema estima a quantidade de matéria seca da parte da planta que será exportada e da que será restituída ao solo (Quadro 1). A partir de dados de acúmulo de matéria seca e de nutrientes em diversas partes da bananeira (Oliveira, 2002), calcularam-se os valores médios de coeficiente de utilização biológica (CUB, que é a quantidade de matéria seca produzida por unidade de nutriente 


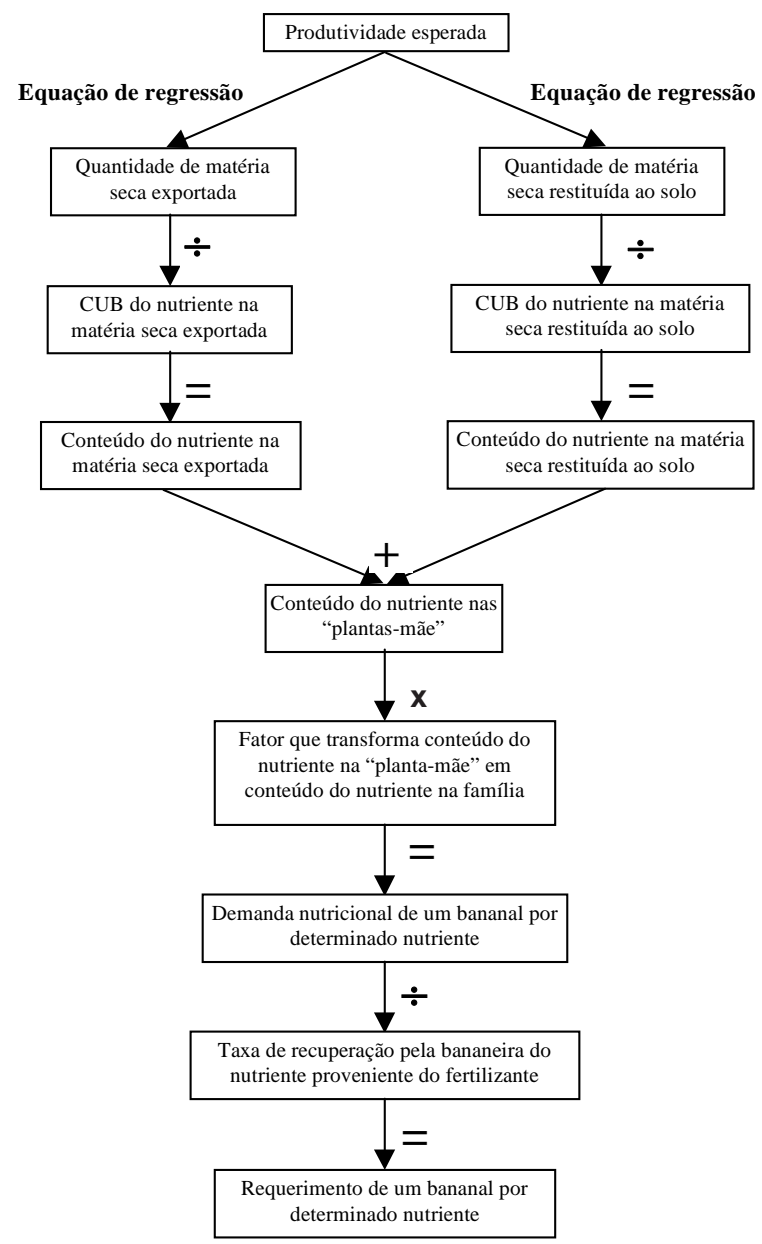

Figura 1. Fluxograma que indica como se estima o requerimento de um bananal por um nutriente no primeiro ciclo de produção, no qual se conduz, em cada touceira, uma "família" (mãefilha-neta) de plantas. acumulado) para cada nutriente, considerando as partes da planta exportada e restituída ao solo (Quadro 2). Dividindo as quantidades de matéria seca exportada erestituída ao sol o pel os respectivos valores de CUB do nutriente, chega-se ao conteúdo do nutrienteem cada uma dessas partes, esomando esses dois val ores, chega-se ao conteúdo do nutriente nas "plantas-mãe".

Em seguida, calcula-se a demanda do nutriente pelas "famílias" (mãe-filha-neta) do bananal (Figura 1), visto que, no campo, geralmente, encontram-se, em cada touceira, três plantas em diferentes estádios de desenvolvimento (uma "família"). Para isso, considera-se que a biomassa da "planta-mãe" na col heita representa cerca 76,4 \% da biomassa da família (Neves et al., 1991) e multiplica-se o teor do nutriente nas "plantas-mãe" por um fator de $1,3089(1 / 0,764)$, dando como resultado a demanda nutricional de um bananal por determinado nutriente no primeiro ciclo. Obtido o valor da demanda nutricional, o requerimento é calculado, dividindo-se esse valor pela taxa de recuperação pela bananeira do nutriente proveniente do fertilizante (Quadro 3). O requerimento de um nutriente pela bananeira é igual à dose desse nutriente necessária para atender à demanda da cultura, sem contabilizar seu suprimento pelo solo.

A partir do segundo ciclo, a bananeira continuará apresentando crescimento vegetativo e reprodutivo, de modo que a demanda nutricional, após o primeiro ciclo, não depende apenas da demanda de exportação, mas também da demanda de crescimento vegetativo. Considerando que a demanda de crescimento vegetativo da planta-mãe no primeiro ciclo é a mesma para o crescimento vegetativo da família nos cicl os seguintes (Oliveira,

Quadro 1. Equações de regressão que estimam as quantidades de matéria seca exportada e restituídas ao solo $\left(\hat{y}\right.$, em $\left.\mathrm{kg} \mathrm{ha}^{-1}\right)$, de acordo com a produtividade esperada $\left(\mathrm{x}, \mathrm{em} \mathrm{t} \mathrm{ha}{ }^{-1}\right)$, para cultivares dos grupos AAA e AAB

\begin{tabular}{|c|c|c|c|}
\hline Grupo & Equação & $\mathbf{R}^{2}$ & $n^{(1)}$ \\
\hline \multicolumn{4}{|c|}{ Matéria seca exportada(2) } \\
\hline \multirow[t]{2}{*}{ AAA } & $\hat{y}=2.638, \forall x<16,5 \mathrm{tha}^{-1}$ & & \\
\hline & $\hat{y}=-286,903+177,287^{* *} x, \forall x \geq 16,5 t^{h a-1}$ & 0,981 & 9 \\
\hline \multirow[t]{2}{*}{$A A B$} & $\hat{\mathrm{y}}=1.846, \forall \mathrm{x}<9,4 \mathrm{tha}^{-1}$ & & \\
\hline & $\hat{y}=21,423+194,109^{* *} x, \forall x \geq 9,4$ t ha-1 $^{-1}$ & 0,943 & 6 \\
\hline \multicolumn{4}{|c|}{ Matéria seca restituída ao sol o(3) } \\
\hline \multirow[t]{3}{*}{ AAA } & $\hat{\mathrm{y}}=3.037, \forall \mathrm{x}<16,5 \mathrm{t} \mathrm{ha}^{-1}$ & & \\
\hline & $\hat{y}=-6.947,89+605,148^{* *} x, \forall 16,5 \leq x \leq 32,3$ tha $^{-1}$ & & \\
\hline & $\hat{y}=12.598, \forall x>32,3 \mathrm{t} \mathrm{ha}^{-1}$ & 0,604 & 7 \\
\hline \multirow[t]{3}{*}{$\mathrm{AAB}$} & $\hat{\mathrm{y}}=7.177, \forall \mathrm{x}<14,7 \mathrm{t} \mathrm{ha}^{-1}$ & & \\
\hline & $\hat{y}=2.313,37+330,827^{* *} x, \forall 14,7 \leq x \leq 39,0$ t ha- $^{-1}$ & & \\
\hline & $\hat{\mathrm{y}}=15.216, \forall \mathrm{x}>39,0 \mathrm{t} \mathrm{ha}^{-1}$ & 0,718 & 7 \\
\hline
\end{tabular}

Fonte: Adaptado de Oliveira (2002).

(1) Número de pares de dados utilizados para ajustar os modelos. (2) Matéria seca exportada = "ráquis feminina" + engaço + frutos.

(3) Matéria seca restituída ao solo = rizoma + pseudocaule + fol has + coração + "ráquis masculina". * e ** Significativos a 5 e 1 \%, respectivamente. 
Quadro 2. Coeficientes de utilização biológica de nutrientes, para bananeiras dos grupos AAA e AAB

\begin{tabular}{|c|c|c|c|c|c|c|c|c|}
\hline \multirow{2}{*}{ Grupo } & \multicolumn{8}{|c|}{ Coeficiente de utilização biológica (CUB) } \\
\hline & $\mathbf{N}$ & $\mathbf{P}$ & $\mathbf{K}$ & $\mathrm{Ca}$ & Mg & $\mathbf{s}$ & B & $\mathbf{Z n}$ \\
\hline & \multicolumn{8}{|c|}{$\mathrm{kg} \mathrm{kg}^{-1}$} \\
\hline & \multicolumn{8}{|c|}{ Biomassa exportada } \\
\hline AAA & 110,7 & 888,0 & 39,1 & $1.166,7$ & 702,1 & $1.224,0$ & $65.923,0$ & $89.006,0$ \\
\hline \multirow[t]{2}{*}{ AAB } & 102,6 & 926,8 & 42,9 & 793,5 & 626,9 & $1.849,9$ & $54.160,0$ & $77.452,0$ \\
\hline & \multicolumn{8}{|c|}{ Biomassa restituída ao solo } \\
\hline AAA & 107,4 & 941,1 & 38,4 & 109,4 & 153,5 & $1.521,4$ & $41.379,0$ & $87.299,0$ \\
\hline$A A B$ & 122,5 & $1.535,9$ & 40,0 & 123,0 & 167,5 & $1.785,2$ & $45.624,0$ & $66.388,0$ \\
\hline
\end{tabular}

Fonte: Adaptado de Oliveira (2002).

Quadro 3. Taxa de recuperação pela bananeira do nutriente proveniente do fertilizante $\left(T R_{B N}\right)$, para os nutrientes considerados no FE RTICALC ${ }^{\circledR}$ - Bananeira ${ }^{(1)}$

\begin{tabular}{|c|c|c|c|c|c|c|c|}
\hline \multicolumn{8}{|c|}{ Nutriente } \\
\hline $\mathbf{N}$ & $\mathbf{P}$ & K & $\mathrm{Ca}$ & Mg & s & B & $\mathrm{Zn}$ \\
\hline 0,65 & 0,35 & 0,80 & 0,80 & 0,80 & 0,45 & 0,45 & 0,35 \\
\hline
\end{tabular}

(1) Em virtude da falta de informações da pesquisa, esses valores
são arbitrários e precisam ser confirmados em futuras pesquisas.
No FERTICALC ${ }^{\circledR}$-Bananeira, considera-se que todos esses nutri-
entes são provenientes de uma fonte solúvel e aplicados
localizadamente. ${ }^{(2)}$ Para $\mathrm{N}$ e $\mathrm{K}$, considera-se que o usuário tem
condições de parcelar as doses desses nutrientes pelo menos a cada
quinze ou trinta dias. No caso do $\mathrm{P}$, B e $\mathrm{Zn}$, deve-se utilizar uma
fonte solúvel e aplicar toda a dose na cova de plantio junto com o
esterco. Quanto ao Ca e ao Mg, no FERTICALC ${ }^{\circledR}$-Bananeira, con-
sidera-se que, antes da instalação de um bananal, deve-se fazer a
calagem em toda a área, incorporando o calcário dolomítico em
todo o volume de solo da camada de $0-20$ cm. Portanto, esses
valores esperados das TR ${ }_{\text {BN }}$, para Ca e Mg, são para a aplicação
localizada de uma fonte solúvel desses nutrientes. No caso do S,
considera-se que o mesmo será fornecido na forma de superfosfato
simples, por ocasião da adubação fosfatada, ou na forma de sulfa-
to de amônio, caso esse adubo venha a ser utilizado para suprir
parte da demanda de $\mathrm{N}$ da bananeira.

2002), no FERTICALC ${ }^{\circledR}$-Bananeira, utiliza-se, a partir do segundo ciclo, o mesmo fluxograma utilizado para o primeiro (Figura 1), apenas não considerando o fator de 1,3089.

O FERTICALC ${ }^{\circledR}$-Bananeira estima, separadamente, osuprimento de um nutrienteoriundo do solo e dos resíduos vegetais. O suprimento de nutrientes é estimado a partir dos teores desses nutrientes indicados na análise química de sol o e o proveniente dos resíduos vegetais a partir da produtividade de bananeira obtida no ciclo anterior. O suprimento de nutrientes provenientes da matéria orgânica do sol o não é contabilizado, porque a matéria orgânica nativa de solos tropicais, particularmente dos mais argilosos, apresenta maior estabilidade (Duxbury et al., 1989) e, no sistema, admite-se que, quantitativamente, esse suprimento é pequeno em relação ao requerimento de nutrientes do bananal. Com isso, espera-se que o teor de matéria orgânica do solo aumente ou, pelo menos, seja mantido em relação ao seu teor original .

Os solos contêm quantidades variadas de nutrientes que podem suprir, parcial ou totalmente, a demanda do bananal. A análise química é a ferramenta mais adequada eutilizada para avaliar a disponibilidade de nutrientes no solo. A disponibilidade de um nutriente é resultante da ação integrada dos fatores I ntensidade (I), Quantidade (Q) e Capaddade Tampão (CT) (Alvarez V., 1996). A CT exerce grande influência na disponibilidade de alguns nutrientes ( $\mathrm{P}, \mathrm{S}$ e $\mathrm{Zn})$ e na de outros ( $\mathrm{K}, \mathrm{Ca}, \mathrm{Mg}$ e $\mathrm{B}$ ) essa influência épequena ou desprezível. Assim, para $\mathrm{P}, \mathrm{S}$ e Zn, é necessário que se considere a CT desses nutrientes no solo para uma adequada estimativa desua disponibilidade. O efeito da CT na disponibilidade desses nutrientes pode ser estimado pel o fósforo remanescente, Prem (Alvarez V. et al., 2000).

No FERTICAL C ${ }^{\circledR}$-Bananeira, recomenda-se adubação para todos os macronutrientes e apenas para os micronutrientes $\mathrm{B}$ e Zn. O suprimento de $\mathrm{N}$ do sol o não é contabilizado pelo sistema, por ser a contribuição do solo para o suprimento desse nutriente à bananeira pequena em relação à sua demanda e por nãose ter utilizada, até então, análise química de $\mathrm{N}$ do solo para fins de recomendação de adubação. Os extratores mais utilizados no País para análise química dos nutrientes considerados no sistema são o Mehlich-1 ( $P, K$ e Zn), Resina ( $P, K$, $\mathrm{Ca}$ e $\mathrm{Mg}$ ), $\mathrm{KCl}\left(\mathrm{Ca}\right.$ e $\mathrm{Mg}$ ), DTPA (Zn), $\mathrm{Ca}\left(\mathrm{H}_{2} \mathrm{PO}_{4}\right)_{2}$ $500 \mathrm{mg} \mathrm{L}^{-1}$ de $\mathrm{P}$, em HOAc $2 \mathrm{~mol} \mathrm{~L}^{-1}$ ou em $\mathrm{H}_{2} \mathrm{O}$ (S) e água quente (B). 
Como oteor de um nutriente indicado na análise química desoloé um índice de disponibilidade enão seu teor realmente disponível, no FERTICALC ${ }^{\circledR}$ Bananeira (Figura 2), divide-se o teor de um nutrienteindicado na análise de sol o pel a respectiva taxa de recuperação do extrator $\left(T R_{E X}\right)$ desse nutriente aplicado ao solo (Quadro 4), obtendo-se a quantidade do nutriente suprida pelo solo $\left(\mathrm{mg} \mathrm{dm}^{-3}\right)$. Em seguida, multiplica-se oval or obtido pel o vol ume de sol o expl orado pelas raízes $\left(V_{\mathrm{ER}}, \mathrm{em} \mathrm{dm}^{3} \mathrm{ha}^{-1}\right)$ e depois divide-se o resultado por um milhão (para transformar $\mathrm{mg} \mathrm{ha}^{-1} \mathrm{em} \mathrm{kg} \mathrm{ha-1)}$, obtendo-se o suprimento do nutriente proveniente do solo $\left(\mathrm{kg} \mathrm{ha}^{-1}\right)$ (Figura 2).

Com base em dados de literatura, no FERTICALC ${ }^{\circledR}$-Bananeira, utiliza-se, para cada nutriente e extrator, valores médios de $T R_{E X}$ (Quadro 4). Para P, S e Zn, ainda é levada em consideração a CT do sol o estimada pelo Prem.

O val or deVS $S_{E R}$ depende da profundidade efetiva do sistema radicular e da superfície do solo efetivamente explorada pelas raízes. Considerando que a bananeira apresenta densidade elevada de

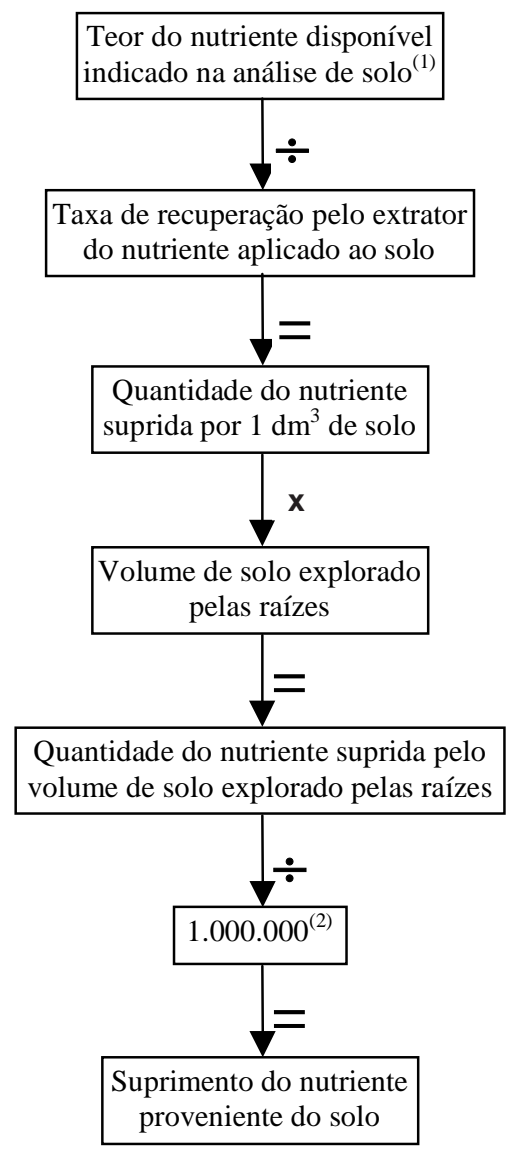

Figura 2. Fluxograma que indica como se estima o suprimento de um nutriente proveniente do solo. ( ${ }^{(1)}$ Os teores de todos os nutrientes deverão ser expressos $\mathrm{em} \mathrm{mg} \mathrm{dm}^{-3}$. (2) Fator para transformar mg ha-1 em kg ha-1). raízes ativas para a absorção de nutrientes até uma profundidade média de $0,30 \mathrm{~m}$ e até um raio médio de 0,70 m a partir do pseudocaule (Avilán R. et al., 1982; Keshava Murthy \& I yengar, 1997; Araya et al., 1998; Garcia, 2000; Araya \& Blanco, 2001), o valor de $\mathrm{VS}_{\mathrm{ER}}$ é dado pela expressão:

$$
\mathrm{VS}_{\mathrm{ER}}=0,3 \cdot \pi \cdot 0,7^{2} \cdot 1000 \cdot \mathrm{NFA}=461,8141 . \mathrm{NFA}
$$

em que $V S_{E R}$ é dado em $d^{3}{ }^{3}$ ha-1 e NFA é o número de famílias por hectare.

A partir dosegundociclo, não há mudança quanto à estimativa do suprimento de nutrientes pel o solo, de modo que o FERTICALC ${ }^{\circledR}$-Bananeira adota o mesmo procedimento utilizado no primeiro ciclo (F igura 2). Como o suprimento de nutrientes para o bananal a partir do segundo cicl o não é proveniente somente do solo, o sistema também contabiliza o suprimento de nutrientes provenientes dos resíduos vegetais.

E m um programa de recomendação de adubação para a bananeira, deve-se contabilizar o suprimento denutrientes provenientes dos resíduos vegetais da bananeira, uma vez que esses resíduos se decompõem rapidamente e servem como fonte de nutrientes para as plantas remanescentes da “família"(Martin-Prével, 1985; Vitti \& Ruggiero, 1985; Vargas \& Flores, 1995). A quantidade de nutrientes imobilizados na biomassa da bananeira na época da col heita é muito el evada e cerca de 59 a $69 \%$ de sua biomassa retorna ao solo após a col heita do cacho (Oliveira, 2002). Seguindo a mesma tendência, mais da metade dos nutrientes acumulados na planta retornam ao solo, com destaque para o $\mathrm{Ca}$ e o $\mathrm{Mg}$, cujas restituições ao sol o podem chegar a 94 e $89 \%$, respectivamente (Oliveira, 2002).

Para estimar o suprimento de um nutriente oriundo dos resíduos da bananeira, a partir do segundo ciclo, é preciso informar ao FERTICALC ${ }^{\circledR}$ Bananeira a produtividade obtida no ciclo anterior, - CUB de cada nutriente na matéria seca restituída ao solo e a fração desses nutrientes que será mineralizada no período entre o ciclo anterior e o ciclo seguinte (Figura 3).

Fornecendo o grupo genômico do cultivar e a produtividade obtida no ciclo anterior, o sistema utiliza equações de regressão (Quadro 1) para estimar a quantidade de matéria seca restituída ao solo. Dividindo a quantidade de matéria seca restituída ao solo pelo CUB do nutriente nessa matéria seca (Quadro 2), obtém-se o conteúdo do nutriente nos resíduos da bananeira.

A próxima variável que deverá ser informada ao FERTICALC ${ }^{\circledR}$-Bananeira éa fração desses nutrientes que será mi neral izada no período entre os dois ciclos deproduçãoda bananeira (FM). Dados experimentais mostraram que, dez semanas após a deposição do pseudocaule na superfície do solo, houve uma mineralização de cerca de 33 \% de sua matéria seca 
Quadro 4. Taxa de recuperação pelo extrator do nutriente aplicado ao solo ( $\left.\hat{y}, \mathrm{em}^{\mathrm{mg} \mathrm{dm}} \mathrm{dm}^{-3} \mathrm{mg} \mathrm{dm}^{-3}\right)$, variável, ou não, com o fósforo remanescente $\left(x, \mathrm{em} \mathrm{mg} \mathrm{L}^{-1}\right)^{(1)}$

\begin{tabular}{|c|c|c|c|}
\hline Nutriente & Extrator & E quação & $\mathbf{R}^{2}$ \\
\hline \multirow{2}{*}{$\mathrm{P}$} & Mehlich-1 & $\hat{y}=0,06728+0,01216^{* *} x$ & 0,681 \\
\hline & Resina & $\hat{\mathrm{y}}=0,419 * * \mathrm{x}^{0,128099}$ & 0,694 \\
\hline \multirow{2}{*}{ K } & Mehlich-1 & $\hat{y}=\bar{y}=0,8020$ & - \\
\hline & Resina & $\hat{y}=\bar{y}=0,7559$ & - \\
\hline \multirow{2}{*}{$\mathrm{Ca}$} & $\mathrm{KCl}$ & $\hat{\mathrm{y}}=\overline{\mathrm{y}}=0,7661$ & - \\
\hline & Resina & $\hat{y}=\bar{y}=0,7661$ & - \\
\hline \multirow{2}{*}{$\mathrm{Mg}$} & $\mathrm{KCl}$ & $\hat{y}=\bar{y}=0,7989$ & - \\
\hline & Resina & $\hat{y}=\bar{y}=0,7989$ & - \\
\hline \multirow[b]{2}{*}{$\mathrm{s}$} & $\mathrm{Ca}\left(\mathrm{H}_{2} \mathrm{PO}_{4}\right)_{2}+\mathrm{HOAC}$ & $\hat{y}=0,0410+0,01700 * * x$ & 0,836 \\
\hline & $\mathrm{Ca}\left(\mathrm{H}_{2} \mathrm{PO}_{4}\right)_{2}+\mathrm{H}_{2} \mathrm{O}$ & $\hat{y}=0,2233+0,01712^{* *} x$ & 0,834 \\
\hline B & Água quente & $\hat{\mathrm{y}}=\overline{\mathrm{y}}=0,4521$ & - \\
\hline \multirow{2}{*}{$\mathrm{Zn}$} & Mehlich-1 & $\hat{y}=0,3603-0,002339^{n s} x+0,0001198^{* *} x^{2}$ & 0,932 \\
\hline & DTPA & $\hat{y}=0,3603-0,002339^{n s} x+0,0001198^{* *} x^{2}$ & 0,932 \\
\hline
\end{tabular}

Fonte: Adaptado de Souza (1999), Morais (1999), Mello (2000), Ferreira et al. (2001) e Santos (2002).

(1) Em virtude da falta de dados para Ca e Mg extraídos pela resina, e Zn pelo DTPA, no FERTICALC ${ }^{\circledR}$-Bananeira, utilizam-se os mesmos val ores de $\mathrm{TR}_{\mathrm{Ex}}$ encontrados para o $\mathrm{KCl}$ e Mehlich-1, respectivamente. ${ }^{\text {ns }} \mathrm{e}^{* *}$ não-significativo e significativo a $1 \%$, respectivamente.

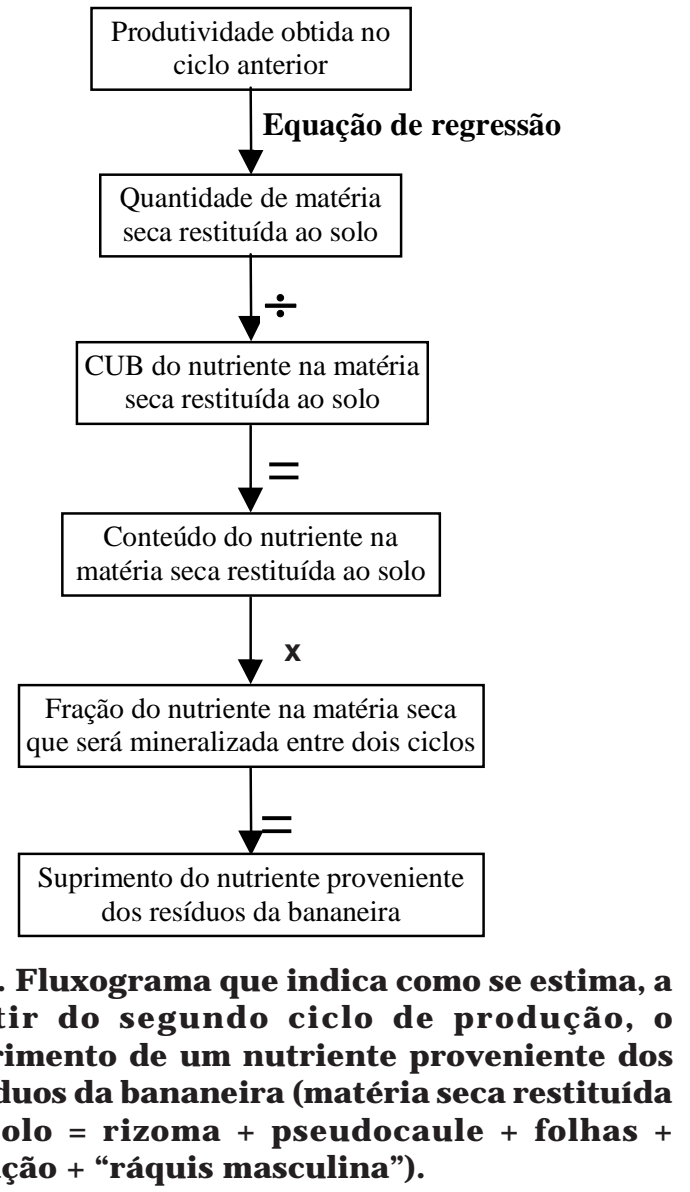

(Turner \& Barkus, 1973). Para fol has, Flores \& Vargas (1994) encontraram um valor de aproximadamente $47 \%$ nesse mesmo período e um valor de $75 \%$ em trinta semanas. Os trabalhos desses autores mostraram que, de modo geral, os val ores das frações dos nutrientes mineralizados são semel hantes aos obtidos para a matéria seca, exceto para o $\mathrm{K}$ e o Zn. Com base nisso, são indicadas as frações dos nutrientes que serão mineralizados no período compreendido entre os dois ciclos de produção (Quadro 5). A fração dos resíduos que não mineraliza no período entre dois ciclos de produção será mineralizada no ciclo posterior, de modo que a restituição dos nutrientes desses resíduos será contabilizada em análises de solo posteriores.

Multiplicando o conteúdo do nutriente na matéria seca restituída ao solo pel o seu respectivo valor de FM, obtém-se a quantidade desse nutriente no solo, proveniente dos resíduos da bananeira, que é igual ao suprimento do nutriente proveniente dos resíduos da bananeira (Figura 3).

Uma vez estimados o suprimento do nutriente proveniente dosolo (SUP So $_{\text {So }}$ ) eo dos resíduos vegetais $\left(S U P_{R E}\right)$, calcula-se o suprimento do nutriente para a bananeira (SUP) pela expressão:

$$
\mathrm{SUP}=\mathrm{SUP}_{\mathrm{SO}}+\mathrm{SUP}_{\mathrm{RE}}
$$

Substituindo os valores de REQ (Figura 1 ) e de SUP (Equação 3) na equação 1 , obtém-se a dose recomendada do nutriente (DR). 
As estimativas das DRs dos nutrientes pelo FERTICALC ${ }^{\circledR}$-Bananeira baseiam-se, em grande parte, no acúmulo de nutrientes absorvidos pela planta desde seu plantio até à colheita. Para o primeiro ciclo, as DRs deverão ser divididas, colocando parte delas na cova de plantio (DRC) e o restante parcelando ao longo do ciclo de produção (DRP). As DRCs visam atender aos níveis críticos de implantação ( $\mathrm{NiCri}_{\text {IMP }}$ ) da bananeira. Pela falta de dados específicos a esta cultura, nesse sistema utilizam-se val ores de $\mathrm{NiCri}_{\text {IMP }}$ recomendados para outra cultura perene, no caso o café (Quadro 6). Sabendo o NiCri Imp do elemento no sol o e o volume de solo da cova, calcula-se o valor de DRC.

Para P, aplica-sea DRC no plantio, mesmo quea DR seja menor que a DRC. A partir do segundo ciclo, não será feita adubação do substrato da cova. Havendo necessi dade, ofertilizante fosfatado deverá ser aplicado na superfície do sol o próximo ao menor

\section{Quadro 5. Fração do nutriente nos resíduos da bananeira mineralizada no período entre dois ciclos (FM), para os nutrientes considerados pelo FERTICALC ${ }^{\circledR}$-Bananeira ${ }^{(1)}$}

\begin{tabular}{cccccccc}
\hline \multicolumn{7}{c}{ Nutriente } \\
\hline $\mathbf{N}$ & $\mathbf{P}$ & $\mathbf{K}$ & $\mathbf{C a}$ & $\mathbf{M g}$ & $\mathbf{S}$ & $\mathbf{B}$ & $\mathbf{Z n}$ \\
\hline \multicolumn{10}{c}{$\mathrm{kg} \mathrm{kg}^{-1}$} \\
\hline 0,65 & 0,60 & 0,85 & 0,55 & 0,55 & 0,60 & 0,50 & 0,30 \\
\hline
\end{tabular}

(1) Valores baseados em dados de Turner \& Barkus (1973) e Flores \& Vargas (1994). Em virtude da carência de dados experimentais, esses valores precisam ser confirmados em futuras pesquisas. rebento da touceira. Para atender ao $\mathrm{NiCri}_{\perp \mathrm{MP}}$ de $\mathrm{P}$ (Quadro 6), é adicionada à cova uma quantidade el evada de P. Tomando como exemplo um solo com $1,89 \mathrm{mg} \mathrm{dm}^{-3}$ de P-Mehlich-1 e Prem $=30,9 \mathrm{mg} \mathrm{L}^{-1}$, o NiCri IMP pelo Mehlich-1 será de $189,92 \mathrm{mg} \mathrm{dm}^{-3}$. A DRC será $=(189,92-1,89) /[0,06728+0,01216$ (Prem) $]$ $=424,42 \mathrm{mg} \mathrm{dm}^{-3}=424,42 \mathrm{~g} \mathrm{~m}^{-3}$. Considerando covas com 0,40 x 0,40 x 0,40 m e uma população de

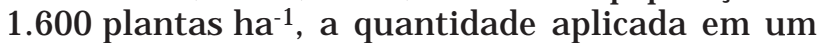
hectare será de $424,42 \mathrm{~g} \mathrm{~m}^{-3} \times 0,064 \mathrm{~m}^{3} \times$ 1.600 plantas ha-1 $=43,46 \mathrm{~kg} \mathrm{ha}^{-1} \mathrm{deP}$.

A concentração de $P$ no solo da cova de plantio $\left(189,92 \mathrm{mg} \mathrm{dm}^{-3}\right)$ diminuirá com o tempo, graças à passagem deP lábil para não-lábil (Novais \& Smyth, 1999) e à absorção de $P$ durante o primeiro ciclo da bananeira. Embora seja difícil prever a quantidade de P que a planta absorverá exclusivamente do solo da cova, é possível estimar a concentração de $\mathrm{P}$ no solo da cova, após determinado tempo $\left(C_{t}\right)$, não considerando a absor ção de P pela planta (Novais \& Smyth, 1999). Adaptando o model o sugerido por esses autores, Freire (2001) e Rosa (2002) estimaram, também, o efeito residual do P aplicado na cova.

No FERTICALC ${ }^{\circledR}$-Bananeira, estima-se o valor de $C_{t}$, para Mehlich-1 ou resina, em função do teor de $P$ inicial $\left(C_{i}\right)$, do Prem, da DRC e do tempo (Quadro 7). Dividindo-se oval or $\mathrm{de}_{\mathrm{t}}\left(\mathrm{mg} \mathrm{dm}^{-3}\right)$ pela $\mathrm{TR}_{\mathrm{EX}}\left(\mathrm{mg} \mathrm{dm}^{-3} / \mathrm{mg} \mathrm{dm}^{-3}\right)$ e multiplicando o resultado pelo volume de solo da cova $\left(\mathrm{dm}^{3} \mathrm{cova}^{-1}\right)$ e pelo número de covas por hectare e dividindo-se o resultado por $10^{6}$, obtém-se o "suprimento de $\mathrm{P}$ residual" (SUP P-Residual, em kg ha-1), que deverá ser acrescentado à estimativa do suprimento de $P$ no segundo ciclo:

$$
S U P_{2^{\circ} \text { Ciclo }}=S U P_{S O}+S U P_{R E}+S U P_{P-R e s i d u a l ~}^{E q . ~(4) ~}
$$

Quadro 6. Níveis críticos de implantação de $P, K, S, B$ e $Z n\left(\hat{y}\right.$, em $\left.\mathrm{mg} \mathrm{dm}^{-3}\right)$, variável, ou não, com o fósforo remanescente $\left(x, \mathrm{em} \mathrm{mg} \mathrm{L}^{-1}\right)^{(1)}$

\begin{tabular}{lll}
\hline Nutriente & \multicolumn{1}{c}{ Extrator } & \multicolumn{1}{c}{ E quação } \\
\hline Mehlich-1 & Resina & $\hat{y}=90,585-0,3018 x+0,1138 x^{2}$ \\
& Mehlich-1 & $\hat{y}=101,31+1,87 x$ \\
K & Resina & $\hat{y}=\bar{y}=200$ \\
S & Ca(H $\left(\mathrm{H}_{2} \mathrm{PO}_{4}\right)_{2}+\mathrm{HOAC}$ & $\hat{\mathrm{y}}=\overline{\mathrm{y}}=190$ \\
$\mathrm{~B}$ & Água quente & $\hat{\mathrm{y}}=10,8+1,539 \mathrm{x}$ \\
$\mathrm{Zn}$ & Mehlich-1 & $\hat{\mathrm{y}}=\overline{\mathrm{y}}=0,1808$ \\
\end{tabular}

Fonte: Adaptado de Prezotti (2001).

(1) Para N, recomenda-se uma dose de $300 \mathrm{mg} \mathrm{dm}^{-3}$. Para Ca e Mg, no FERTICALC ${ }^{\circledR}$-Bananeira, considera-se que os mesmos são supridos suficientemente pela calagem realizada antes do plantio. 
Quadro 7. Equações que estimam a concentração de $\mathbf{P}$ no solo da cova $\left(\hat{\mathrm{C}}_{\mathrm{t}}, \mathrm{em} \mathrm{mg} \mathrm{dm} \mathbf{~}^{-3}\right)$, em função da concentração inicial de $P\left(C_{i}, \mathrm{em} \mathrm{mg} \mathrm{dm}^{-3}\right)$, do fósforo remanescente (Prem, em $\left.\mathrm{mg} \mathrm{L}^{-1}\right)$, da dose de $P$ aplicada no plantio (DRC, em $\mathrm{mg} \mathrm{dm}^{-3}$ ) e do tempo (t, em dias)

\begin{tabular}{ll}
\hline Extrator & Equação(1) \\
\hline Mehlich-1 & $\hat{C}_{t}=C_{i}+\{0,06728+0,01216($ Prem $\left.)\} D R C-C_{i}\right\} e^{0,0013(t)}$ \\
Resina & $\left.\hat{C}_{t}=C_{i}+\left\{0,419(\text { Prem })^{0,128099}\right] D R C-C_{i}\right\} e^{0,0013(t)}$
\end{tabular}

Fonte: Adaptado de Novais \& Smyth (1999).

(1) Nessas equações, e é a base do logaritmo neperiano.

A partir do terceiro ciclo, a contribuição do P residual será muito pequena, visto que a absorção de $\mathrm{P}$ pela bananeira nos dois primeiros ciclos contribui para diminuir o efeito residual do $\mathrm{P}$ adicionado na cova. Por outrolado, a planta que vai produzir no terceiro cicl o terá grande parte de suas raízes distantes da cova, de modo que sua absorção de $\mathrm{P}$ proveniente da cova será muito pequena. No exemplo citado, considerando que a duração do primeiro ciclo é de um ano (365 dias), o valor de $C_{t}$ para Mehlich-1 será:

$$
\begin{gathered}
C_{t}=1,89+\{0,06728+0,01216(30,9)] \times 424,42- \\
1,89\} e^{0,0013(365)}=117,70 \mathrm{mg} \mathrm{dm}^{-3}
\end{gathered}
$$

Dividindo o valor de $C_{t}$ pela $T R_{E X}$, obtém-se o SUP $_{\text {P-Residual }}=117,70 /[0,06728+0,01216($ Prem $)]=$ $265,67 \mathrm{mg} \mathrm{dm}^{-3}$. Para transformar esse valor em kg ha-1, multiplica-se esse val or pel o volume de solo da cova $\left(64 \mathrm{dm}^{3}\right)$, pelo número de covas ha-1 (1.600) e depois divide-se o resultado por $10^{6}$ :

$$
\begin{aligned}
\text { SUP P-Residual }_{\text {P }} & =(265,67 \times 64 \times 1.600) / 10^{6} \\
& =27,20 \mathrm{~kg} \mathrm{ha}^{-1} \mathrm{de} P
\end{aligned}
$$

Portanto, consi derando os seguintes val ores para o segundo ciclo: REQ $=65,54 \mathrm{~kg} \mathrm{ha}^{-1}, \mathrm{SUP}_{\mathrm{so}}=$ $9,46 \mathrm{~kg} \mathrm{ha}^{-1}$ eSUP $_{\mathrm{RE}}=16,43 \mathrm{~kg} \mathrm{ha}^{-1}$, a DR deP para o segundo ciclo será:

$$
\begin{aligned}
\text { DRP }_{2 \text { - Ciclo }} & =65,54-(9,46+16,43+27,20) \\
& =12,45 \mathrm{~kg} \mathrm{ha}^{-1} \mathrm{de} P
\end{aligned}
$$

\section{Simulações do sistema}

Para realizar simulações com o FERTICALC ${ }^{{ }_{-}}$ Bananeira, tomaram-se resultados analíticos de trinta amostras de solos analisadas no laboratório de rotina do Departamento deSol os da Universidade Federal de Viçosa (Oliveira, 2002). Realizaram-se simulações para verificar as variações das doses dos nutrientes recomendadas em função da produtividade esperada e do teor desses nutrientes no solo. Para bananeiras dogrupo $A A A$, variou-sea produtividade esperada de 16,5 a 70,0 tha-1 e, para bananeiras do grupo $A A B$, de 9,4 a 50 t ha-1. $^{-1}$.
Não são apresentadas simulações para as doses recomendadas de $\mathrm{Ca}$ e $\mathrm{Mg}$, porque o FERTICALC ${ }^{\circledR}$ Bananeira considera que esses nutrientes geralmente são supridos adequadamente pela calagem realizada antes do plantio.

\section{RESULTADOS E DISCUSSÃO}

As si mulações real izadas mostraram que as doses recomendadas dos nutrientes aumentaram com o aumento da produtividade esperada, sendo maior no primeiro ciclo (Figuras 4 e 5). Para P, o efeito residual da adubação da cova, realizada no primeiro ciclo, aumenta o suprimento desse nutriente no segundo ciclo, levando o sistema a não recomendar este nutriente, ou recomendar pequenas doses, apenas para produtividades el evadas (Figura 4). As mudanças de declividades das curvas apresentadas (Figuras 4 e 5 ) são devidas às restrições para as equações apresentadas no quadro 1. Para o grupo AAA, as declividades das curvas diminuem quando a produtividade esperada é superior a $32,0 \mathrm{t} \mathrm{ha}^{-1}$. Para o grupo $A A B$, a declividade é maior na faixa entre 14,7 e 39,0 $\mathrm{t} \mathrm{ha}^{-1}$ e menor fora dela. A DR de $\mathrm{P}_{2} \mathrm{O}_{5}$ no primeiro ciclo não varia, enquanto a produtividade esperada for baixa o suficiente para causar um valor de DR menor que DRC (Figura 4).

Quanto à variação das doses dos nutrientes em razão de seus teores no solo, elas diminuem continuamente à medida que os teores dos nutrientes no solo aumentam, tanto no primeiro ciclo quanto no segundo (Figuras 6 e 7). Esse efeito émais evidente para os nutrientes demandados pela planta em pequenas quantidades, como $\mathrm{B}$ e $\mathrm{Zn}$ (Figura 7). Para P, S e Zn, as doses recomendadas podem ser diferentes, para os mesmos teores desses nutrientes no solo (Figuras 6 e 7), uma vez que seus suprimentos também dependem da capacidade tampão do solo. Para todos os nutrientes, a dose recomendada é maior no primeiro ciclo que no segundo (Figuras 6 e 7).

Ao contrário do FERTICALC ${ }^{\circledR}$-Bananeira, as tabel as de recomendação deadubação em uso no País 

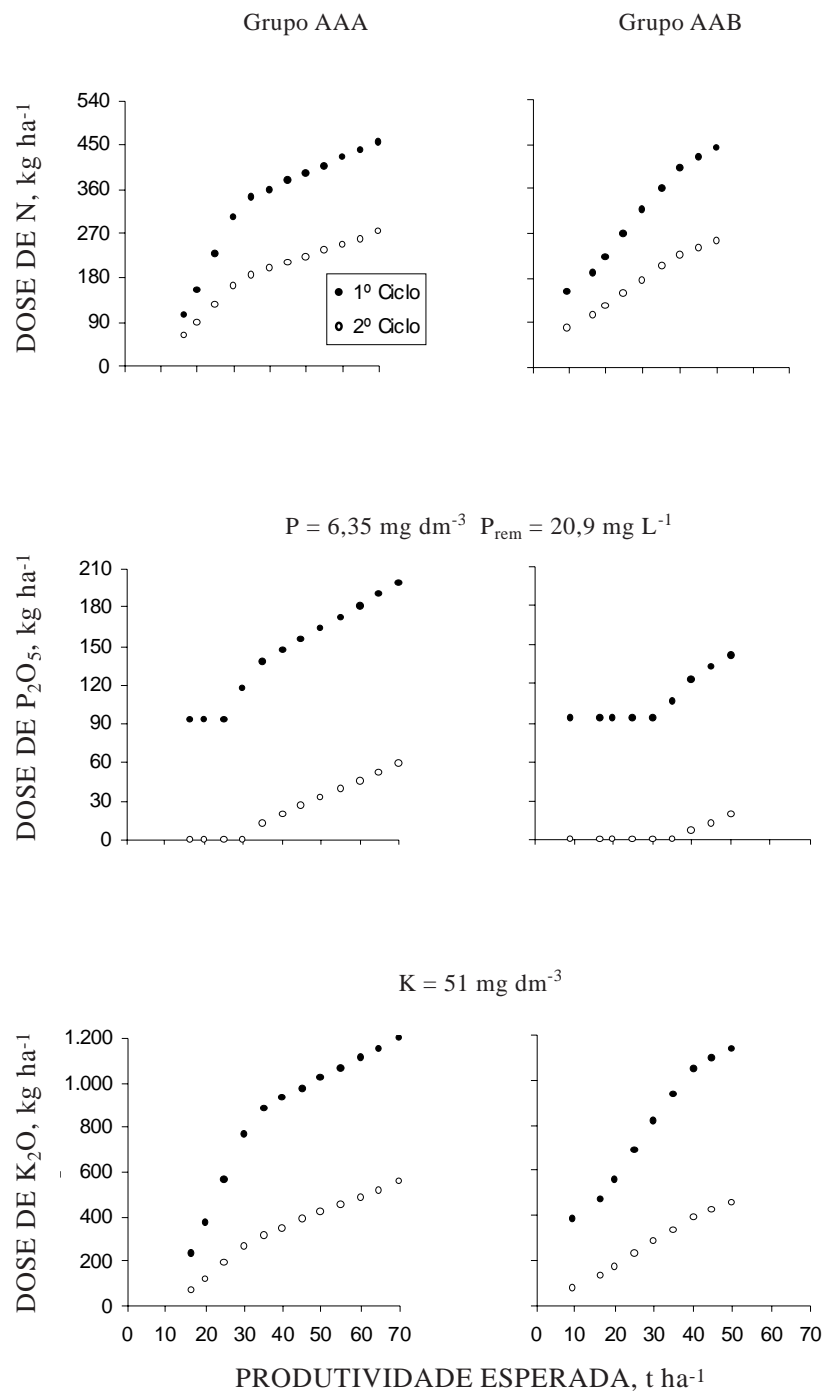

Figura 4. Doses de $\mathrm{N}, \mathrm{P}_{2} \mathrm{O}_{5}$ e $\mathrm{K}_{2} \mathrm{O}$ recomendadas pelo FERTICALC ${ }^{\circledR}$-Bananeíra em função da produtividade esperada, para bananeiras dos grupos AAA e AAB, no primeiro e no segundo ciclo.

(CEFS/BA, 1989; UFC, 1993; CFS RS/SC, 1995; Teixeira et al., 1996; Gonzaga Neto et al., 1998; Souza et al., 1999; Borges et al., 2002; Borges \& Costa, 2002) não consideram que as doses recomendadas dos nutrientes variam de forma contínua com a produtividade esperada e com os teores ea capacidade tampão dos nutrientes no solo. O que essas tabel as consideram são faixas de teores dos nutrientes no solo, na maioria das vezes não associadas com faixas de produtividades esperadas e, ou, com faixas de teores de argila ou de Prem.

As DRs de $\mathrm{K}_{2} \mathrm{O}$ para o primeiro ciclo parecem ser excessivas (Figuras 4 e 6), podendo ser dadas duas explicações para este fato. A primeira é que possivelmente o FERTICALC ${ }^{\circledR}$-Bananeira esteja superestimando o teor de $\mathrm{K}$ na planta e o requerimento deste nutriente pela bananeira
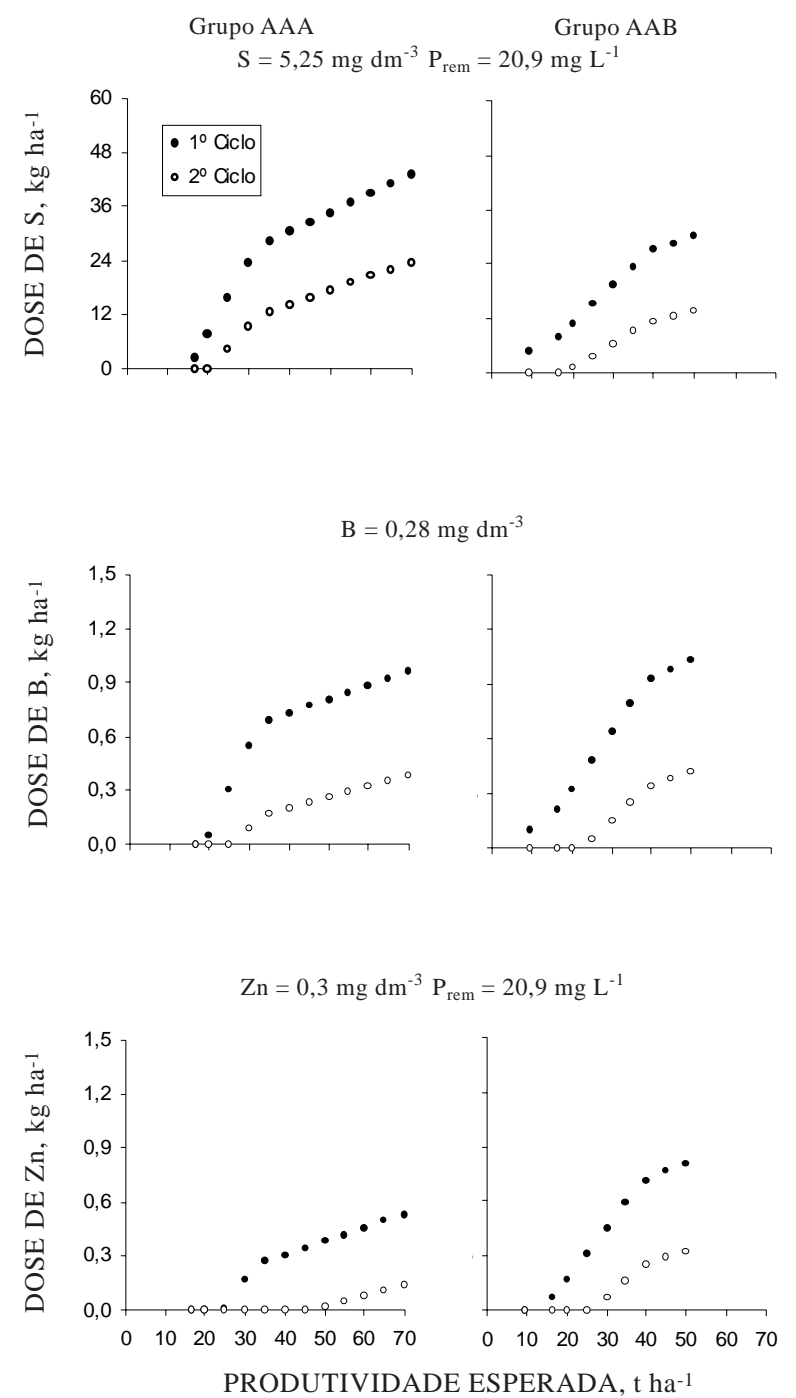

Figura 5. Doses de enxofre, boro e zinco recomendadas pelo FERTICAL C ${ }^{\circledR}$-Bananei ra em função da produtividade esperada, para bananeiras dos grupos AAA e AAB, no primeiro e no segundo ciclo.

(Figura 1), pela utilização de valores de CUB para $\mathrm{K}$ possivel mente baixos (Quadro 2). Baixos valores deCUB deK podem ser determinados peloacúmulo excessivo de K na planta (consumo de luxo), gerando valores el evados de demanda de K pela planta. A segunda explicação deve-seà não-contabil ização pelo FERTICALC ${ }^{\circledR}$-Bananeira do suprimento de $\mathrm{K}$ nãotrocável do solo para a planta. Segundo Chiba \& Natale (2003), essa forma de K do solo pode contribuir para osuprimento deK para a bananeira.

Futuras pesquisas para determinar as quantidades e partição de matéria seca e de $K$ acumuladas na planta na época da colheita, bem como o suprimento de K não-trocável do solo para a bananeira, produzirão dados que poderão ser utilizados pelo FERTICALC ${ }^{\circledR}$-Bananeira para corrigir esse problema em futuras versões do sistema. 

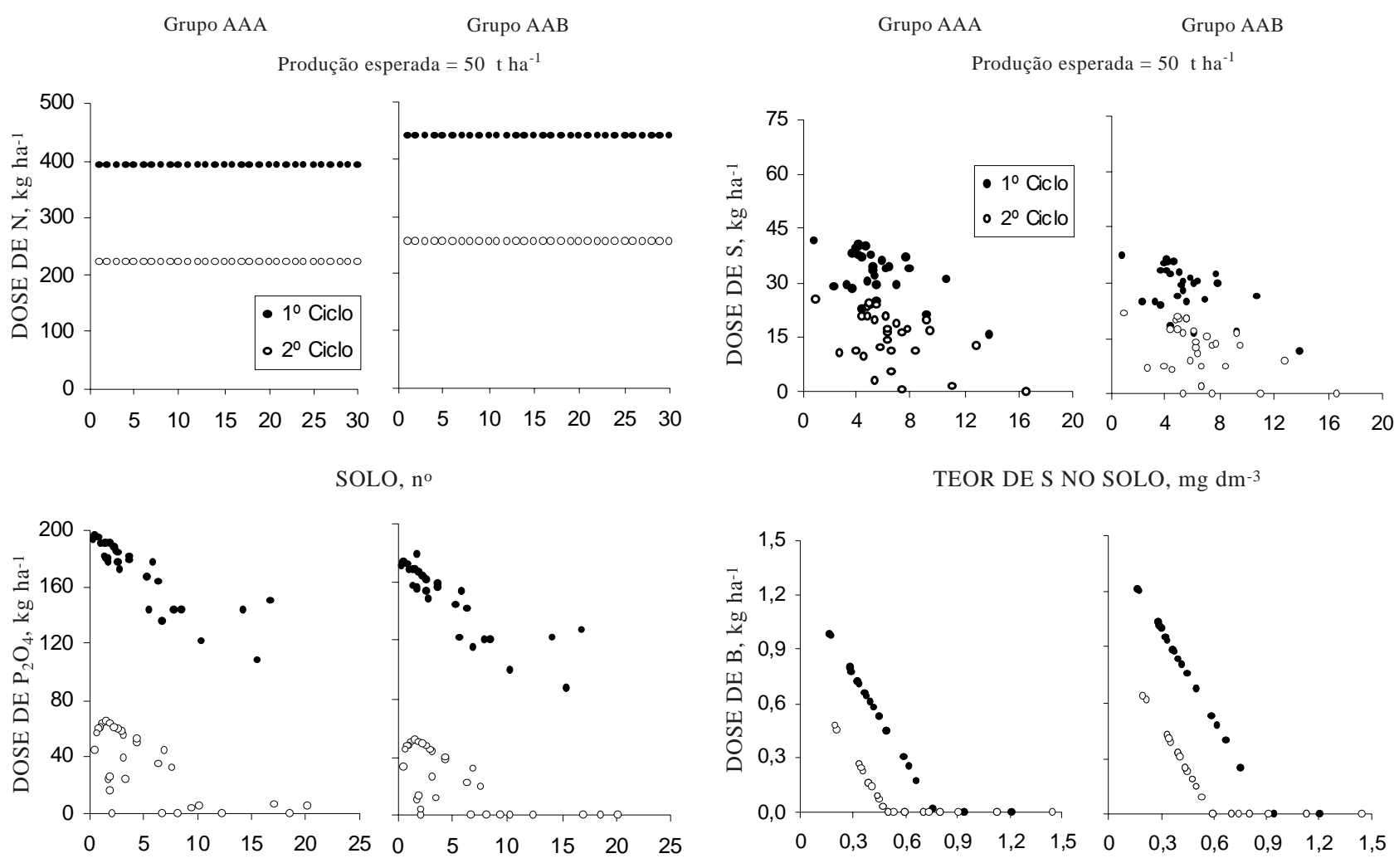

TEOR DE P NO SOLO, $\mathrm{mg} \mathrm{dm}^{-3}$

TEOR DE B NO SOLO, $\mathrm{mg} \mathrm{dm}^{-3}$

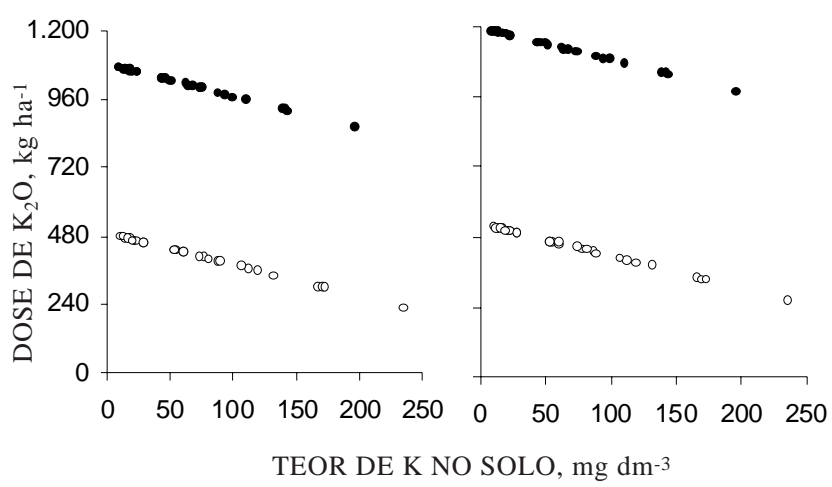

Figura 6. Doses de $\mathrm{N}, \mathrm{P}_{2} \mathrm{O}_{5}$ e $\mathrm{K}_{2} \mathrm{O}$ recomendadas pelo FERTICALC ${ }^{\circledR}$-Bananeira, em função dos teores desses nutrientes no solo, para bananeiras dos grupos AAA e AAB, no primeiro e no segundo ciclo (Para nitrogênio, considerou-se o solo como variável independente, por ainda não se dispor de análise de solo para esse nutriente).

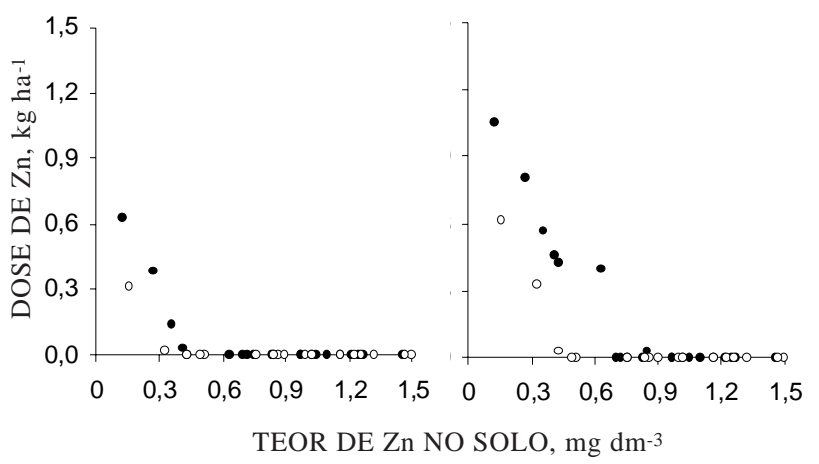

Figura 7. Doses de enxofre, boro e zinco recomendadas pelo FERTICALC ${ }^{\circledR}$-Bananeira, em função dos teores desses nutrientes no solo, para bananeiras dos grupos AAA e AAB, no primeiro e no segundo ciclo.

\section{CONCLUSÕES}

1. As simulações realizadas mostraram que as doses de nutrientes recomendadas pelo FERTICALC ${ }^{\circledR}$-Bananeira relacionam-sesatisfatoriamente com a produtividade esperada e com os teores ecom a capacidade tampão dos nutrientes no solo.

2. Considerando a lógica envolvida em sua constituição e as variáveis utilizadas na modelagem do FERTICALC ${ }^{\circledR}$-Bananeira, este sistema constitui uma importante alternativa para estimar doses de nutrientes a serem recomendadas para a cultura da bananeira, sendo muito propenso a ajustes futuros, mediante a incorporação de novos resultados de pesquisa em futuras versões do sistema. 


\section{LITE RATURA CITADA}

ALVAREZ V., V.H. Correlação e calibração de métodos de análisedesolos. In: ALVAREZV., V.H.; FONTES, L.E.F. \& FONTES, M.P.F., eds. O sol o nos grandes domínios morfoclimáticos do Brasil e o desenvolvimento sustentado. Viçosa, Sociedade Brasileira de Ciência do Solo, 1996. p.615-646.

ALVAREZ V., V.H.; NOVAIS, R.F.; DIAS, L.E. \& OLIVEIRA, J .A. Determinação e uso do fósforo remanescente. Bol. Inf. Soc. Bras. Ci. Solo, 25:27-32, 2000.

ALVES, E.J . \& OLIVEIRA, M.A. Práticas culturais. In: ALVES, E.J., ed. A cultura da banana: aspectos técnicos, socioeconômi cos eagroindustriais. Brasília, Embrapa, 1999. p.335-351.

ARAYA, M. \& BLANCO, F. Changes in the stratification and spatial distribution of the banana (Musa AAA cv. Grand Naine) root system of poor, regular, and good developed plants. J . Plant Nutrt., 24:1676-1693, 2001.

ARAYA, M.; VARGAS, A. \& CHEVES, A. Changes in distribution of roots of banana (Musa AAA cv. Valery) with plant height, distance from the pseudostem and soil depth. J. Hortic. Sci. Biotechnal., 73:437-440, 1998.

AVILÁN R., L.; MENESES R., L. \& SUCRE, R.E. Distribución radical del banano bajo diferentes sistemas de manejo de suelos. Fruits, 37:103-110, 1982.

BARROS, N.F.; NOVAIS, R.F.; TEIXEIRA, J .L. \& FERNANDES FILHO, E.I. NUTRICALC 2.0 - Sistema para cálculo del balance nutricional y recomendación de fertilizantes para el cultivo de eucalipto. Bosque, 16:129-131, 1995.

BOOTE, K.J .; J ONES, J .W. \& PICKERING, N.B. Potential uses and limitations of crop models. Agron. J ., 88:704-716, 1996.

BORGES, A.L. \& COSTA, E.L. Requerimentos de nutrientes para fertirrigação: 2. Banana. In: BORGES, A.L.; COELHO, E.F. \& TRINDADE, A.V., orgs. Fertirrigação em fruteiras tropicais. Cruz das Almas, Embrapa Mandioca e Fruticultura, 2002. p.77-84.

BORGES, A.L.; OLIVEIRA, A.M.G. \& SOUZA, L.S. Solos, nutrição e adubação. In: ALVES, E.J., ed. A cultura da banana: aspectos técnicos, socioeconômicos e agroindustriais. Brasília, Embrapa, 1999. p.197-260.

BORGES, A.L.; RAIJ, B. van; MAGALHÃES, A.F.J. \& BERNARDI, A.C.C. Nutrição e adubação da bananeira irrigada. Cruz das Almas, Embrapa Mandioca e Fruticultura, 2002. 8p. (Circular Técnica, 48)

CARVALHO, F.T. Sistema de interpretação de análise de solo para recomendação de corretivos e fertilizantes para a cultura do milho. Viçosa, Universidade Federal de Viçosa, 2000. 93p. (Tese de Mestrado)

CHIBA, M.K. \& NATALE, W. Contribuição de formas não trocáveis de potássio na nutrição da bananeira. In: CONGRESSO BRASILEIRO DE CIÊNCIA DO SOLO, 29., Ribeirão Preto, 2003. Anais. Botucatu, Universidade Estadual Paulista, 2003. 3p. CD-ROM

COMISSÃO DE FERTILIDADE DO SOLO - CFS RS/SC. Recomendações de adubação e calagem para os estados do Rio Grande do Sul e de Santa Catarina. Passo Fundo, Núcleo Regional Sul, 1995. 224p.
COMISSÃO ESTADUAL DE FERTILIDADE DO SOLO - CEFS BA. Manual deadubação e calagem para o estado da Bahia. Salvador, CEPLAC/EMATERBA/EMBRAPA/ EPABA/ NITROFÉRTIL, 1989. 173p.

DOURADO NETO, D.; TERUEL, D.A.; REICHARDT, K.; NIELSEN, D.R.; FRIZZONE, J .A. \& BACCHI, O.O.S. Principles of crop modeling and simulation: I. Uses of mathematical models in agricultural science. Sci. Agric., 55:46-50, 1998a.

DOURADO NETO, D. TERUEL, D.A.; REICHARDT, K.; NIELSEN, D.R.; FRIZZONE, J.A. \& BACCHI, O.O.S. Principles of crop modeling and simulation: II. The implications of the objective in model development. Sci. Agric., 55:51-57, 1998b.

DUXBURY, J .M.; SMITH, M.S. \& DORAN, J .W. Soil organic matter as a source and a sink of plant nutrients. In: COLEMAN, S.C., OADES, J.M. \& UEHARA, G., eds. Dynamics of soil organic matter in tropical ecosystems. Honolulu, Niftal project, 1989. p.33-67.

FERREIRA, G.B.; FONTES, R.L.F.; FONTES, M.P.F.\& ALVAREZ V., V.H. Influência de algumas características do solo nos teores de boro disponível. R. Bras. Ci. Solo, 25:91-101, 2001

FLORES, S.C.L. \& VARGAS, V.R. Liberación de nutrimentos por los residuos vegetales en suel os bajo cultivo de banano en la Zona Atlántica de Costa Rica. In: CONTRERAS, M.A.; GUZMÁN, I.A. \& CARRASCO, L.R., eds. REUNIÓN DE LA ASOCIACIÓN PARA LA COOPERACIÓN EN INVESTIGACIÓN DE BANANO EN EL CARIBE Y EN AMÉRICA TROPICAL - ACORBAT, 10., Tabasco, 1991. Memorias. San J osé, CORBANA, 1994. p.59-64.

FREIRE, F.J . Sistema para cálculo do balanço nutricional e recomendação de corretivos e fertilizantes para cana-deaçúcar. Viçosa, U niversidade F ederal de Viçosa, 2001. 144p. (Tese de Doutorado)

GARCIA, R.V. Sistema radicular de bananeira irrigada por aspersão convencional e microaspersão no Projeto J aíba, MG. Viçosa, Universidade Federal de Viçosa, 2000. 47p. (Tese de Mestrado)

GEYPENS, M. \& VANDENDRIESSCHE, H. Advisory systems for nitrogen fertilizer recomendations. Plant Soil, 181:3138, 1996.

GONZAGA NETO, L.; PEREIRA, J.R. \& SILVA, D.J . Banana (I rrigada). In: CAVALCANTI, F.J .A., coord. Recomendações de adubação para o estado de Pernambuco: 2 a aproximação. Recife, Empresa Pernambucana de Pesquisa Agropecuária, 1998. p.115.

KESHAVA MURTHY, S.V. \& IYENGAR, B.R.V. Root distribution and morphology in some banana (Musa $X$ paradisiacal ) varieties. Ind. J . Agric. Sci., 67:495-499, 1997.

LAHAV, E. Banana nutrition. In: GOWEN, S., ed. Bananas and plantains. London, Chapman \& Hall, 1995. p.258-316.

LÓPEZ M., A. \& ESPINOSA M., J. Manual de nutrición y fertilización del banano. Quito, CORBANA/Instituto de la Potasa y el Fósforo, 1995. 82p.

MARTIN-PRÉVEL, P. Exigências nutricionais da bananicultura. In: SIMPÓSIO BRASILEIRO SOBRE BANANICULTURA, 1., J aboticabal, 1984. Anais. J aboticabal, Universidade Estadual Paulista, 1985. p.118-134. 
MELLO, M.S. Sistema de interpretação de análise de solo e de recomendação de calagem e fertilizante para a cultura de tomate. Viçosa, Universidade F ederal de Viçosa, 2000. 91p. (Tese de Mestrado)

MONTEITH, J .L. The quest for balancein crop modeling. Agron. J ., 88:695-697, 1996.

MORAIS, E.R.C. Formas de potássio em solos do Estado de Minas Gerais e sua disponibilidade para plantas de milho. Viçosa, Universidade Federal de Viçosa, 1999. 85p. (Tese de Mestrado)

NEVES, R.L.L.; FERREYRA, F.F.H.; MACIEL, R.F.P. \& FROTA, J .N.E. Extração de nutrientes em banana (Musa sp.) cv. Pacovan. Ci. Agron., 22:115-120, 1991.

NOVAIS, R.F. \& ALVAREZ V., V.H. Sistemas de interpretação de análise de solo e recomendação de fertilizantes: muito simples ou muito complexo. In: REUNIÃO BRASILEIRA DE FERTILIDADE DO SOLO E NUTRIÇÃO DE PLANTAS, 24.; REUNIÃO BRASILEIRA SOBRE MICORRIZAS, 8.; SIMPÓSIO BRASILEIRO DE MICROBIOLOGIA DO SOLO, 6.; REUNIÃO BRASILEIRA DE BIOLOGIA DO SOLO, 3., Santa Maria, 2000. Anais. Santa Maria, Sociedade Brasileira de Ciência do Solo/ Universidade Federal de Santa Maria, 2000. CD-ROM

NOVAIS, R.F. \& SMYTH, T.J . Fósforo em solo e planta em condições tropicais. Viçosa, UniversidadeF ederal deViçosa, 1999. 399p.

NOVAIS, R.F.; PREZOTTI, L.C.; ALVAREZ V., V.H.; CANTARUTTI, R.B. \& BARROS, N.F. FERTICALC Sistema para recomendação de corretivos e fertilizantes para a cultura do caféarábica. Viçosa, UniversidadeF ederal de Viçosa, 2002. CD-ROM

OLIVEIRA, F.H.T. Sistema para recomendação de calagem e adubação para a cultura da bananeira. Viçosa, Universidade Federal de Viçosa, 2002. 78p. (Tese de Doutorado)

PASSIOURA, J.B. Simulation models: science, snake oil, education, or engineering? Agron. J ., 88:690-694, 1996.

POSSAMAI, J .M. Sistema de recomendação de corretivos e fertilizantes para a cultura do algodoeiro. Viçosa, Universidade Federal de Viçosa, 2003. 91p. (Tese de Mestrado)

PREZOTTI, L.C. Sistema para recomendação de corretivos e de fertilizantes para a cultura do café arábica. Viçosa, Universidade Federal de Viçosa, 2001. 93p. (Tese de Doutorado)

RAFFAELI, V. Sistema de interpretação de análise de solo e de recomendação de nutrientes para arroz irrigado. Viçosa, Universidade Federal de Viçosa, 2000. 76p. (Tese de Mestrado)

RAO, P.S.C.; J ESSUP, R.E. \& HORNSBY, A.G. Simulation of nitrogen in agro-ecosystems: criteria for model selection and use. Plant Soil, 67:35-43, 1982.
ROSA, G.N.G.P. Sistema de recomendação de corretivos e fertilizantes para a cultura do coqueiro. Viçosa, Universidade Federal de Viçosa, 2002. 73p. (Tese de Mestrado)

SANTOS, F.C. Sistema de recomendação de corretivos e fertilizantes para a cultura da soja. Viçosa, Universidade Federal de Viçosa, 2002. 100p. (Tese de Mestrado)

SANTOS, H.Q. Sistema para cálculo do balanço de nutrientes e recomendação de calagem e adubação de pastagem para bovinos de corte. Viçosa, Universidade Federal de Viçosa, 2003. 138p. (Tese de Doutorado)

SOUTO, R.F.; RODRIGUES, M.G.V.; RUGGIERO, C. \& MENEGUCCI, J .L.P. Novas perspectivas em sistemas de implantação, condução e práticas de manejo da bananeira. Inf. Agropec., 20:10-15, 1999.

SOUZA, M.; GUIMARÃES, P.T.G.; CARVALHO, J.G. \& FRAGOAS, J.C. Banana prata anã. In: RIBEIRO, A.C.; GUIMARÃES, P.T.G. \& ALVAREZ V., V.H., eds. Recomendações para o uso de corretivos e fertilizantes em Minas Gerais: 5a aproximação. Viçosa, Comissão de Fertilidade do Solo do Estado de Minas Gerais, 1999. p.217218.

SOUZA, R.B. Níveis críticos de enxofre em sol os e em fol has de cultivares de café. Viçosa, U niversidade F ederal de Viçosa, 1999. 88p. (Tese de Doutorado)

STANFORD, G. Rationale for optimum nitrogen fertilization in corn production. J . Environ. Qual., 2:159-166, 1973.

TEIXEIRA, L.A.J .; SPIRONELLO, A.; QUAGGIO, J.A. \& FURLANI, P.R. Banana. In: RAIJ , B. van; CANTARELLA, H.; QUAGGIO, J.A. \& FURLANI, A.M.C., eds. Recomendações de adubação e calagem para o estado de São Paulo. Campinas, Instituto Agronômico \& Fundação IAC, 1996. p.131-132. (Boletim Técnico, 100)

TOMÉ J ÚNIOR, J .B. \& NOVAIS, R.F. Utilização de modelos como alternativas às tabelas de recomendação de adubação. Bol. Inf. Soc. Bras. Ci. Solo, 25:8-11, 2000.

TOMÉ J ÚNIOR, J .B. U ma nova abordagem nas recomendações de adubação. Viçosa, U niversidade Federal de Viçosa, 2004. 133p. (Tese de Doutorado)

TURNER, D.W. \& BARKUS, B. Loss of mineral nutrients from banana pseudostems after harvest. Trop. Agric., 50:229233, 1973.

UNIVERSIDADE FEDERAL DO CEARÁ - UFC. Recomendações de adubação e calagem para o estado do Ceará. Fortaleza, 1993. p.138-139.

VARGAS V., R. \& FLORES, S.C.L. Redistribución nutricional de los residuos de hojas, venas de hojas, pseudotallo y pinzote de banano (Musa AAA) en fincas de diferentes edades de cultivo. R. Corbana, 20:33-47, 1995.

VITTI, G.C. \& RUGGIERO, C. Aproveitamento do engaço, coração e ráquis, como fonte de nutrientes. In: SI MPÓSIO BRASILEIRO SOBRE BANANICULTURA, 1., J aboticabal, 1984. Anais. J aboticabal, Universidade Estadual Paulista, 1985. p.392-399. 